\title{
Syndecan-4 Deficiency Increases Susceptibility to $\kappa$-Carrageenan-Induced Renal Damage
}

\author{
Kazuhiro Ishiguro, Kenji Kadomatsu, Tetsuhito Kojima, Hisako Muramatsu, \\ Seiichi Matsuo, Kazuo Kusugami, Hidehiko Saito, and Takashi Muramatsu
}

Department of Biochemistry (KI, KKa, HM, TM), First Department of Internal Medicine (KI, TK, KKu, HS), and Third Department of Internal Medicine (SM), Nagoya University School of Medicine, Nagoya, and Department of Medical Technology (TK), Nagoya University School of Health Sciences, Nagoya, Japan

\begin{abstract}
SUMMARY: The expression and roles of syndecan-4 in the kidney were investigated. Syndecan-4 expression was detected in the ureteric bud invaginating into the metanephric mesenchyme at 11.5 gestational days, and remained in the collecting ducts, distal renal tubules, glomeruli, and some capillaries between renal tubules until the mature kidney stage. However, organogenesis of the kidney was normal in syndecan-4-deficient (Synd4[-/-]) mice. Although most renal functions of Synd4(-/-) mice were not impaired, a significant increase in susceptibility to $\kappa$-carrageenan-induced renal damage was observed in these mice. $\kappa$-Carrageenan was heavily deposited in the collecting ducts of Synd4(-/-) mice and caused obstructive nephropathy, leading to death of 7 of 24 Synd4(-/-) mice within 7 days after administration, whereas none of 24 Synd4(+/+) mice died. After administration of $\kappa$-carrageenan, blood urea nitrogen of Synd4(-/-) mice was significantly higher than that of Synd4(+/+) mice. Thus, syndecan-4 may function to prevent $\kappa$-carrageenan deposition in the collecting ducts. (Lab Invest 2001, 81:509-516).
\end{abstract}

Syndecan-4 (Ryudocan) is a type I integral mem$\checkmark$ brane heparan sulfate proteoglycan (HSPG), which was originally isolated from cloned rat microvascular endothelial cells as an antithrombin-binding molecule, and is now known to be a member of the syndecan family (Kojima et al, 1992a, 1992b). Syndecan-4 binds to basic fibroblast growth factor (bFGF), midkine, and tissue factor pathway inhibitor via its heparan sulfate chains (Kojima et al, 1996), and is thought to be involved in various biologic functions such as signaling of bFGF (Horowitz and Simons, 1998), anticoagulation (Ishiguro et al, 2000a; Kojima et al, 1992a), and focal adhesion formation (Ishiguro et al, 2000b; Woods and Couchman, 1994). A previous study demonstrated that syndecan-4 is expressed in various tissues, and its level of expression in the kidney is stronger than those of other syndecan family members (Kim et al, 1994). Thus, syndecan-4 is thought to play certain roles in maintaining renal function. Moreover, it has been reported that proteoglycans, especially sulfated proteoglycans, are involved in organogenesis of the kidney (Davies et al, 1995; Kispert et al, 1996).

Received November 27, 2000

Supported with Grants-in-aid for scientific research (10557090, 10670942, 10178102, and 10CE2006) by the Ministry of Education, Science, Sports and Culture, and for research on specific diseases by the Ministry of Health and Welfare.

Address reprint requests to: Dr. Takashi Muramatsu, Department of Biochemistry, Nagoya University School of Medicine, 65 Tsurumaicho, Showa-ku, Nagoya, Aichi, 466-8550, Japan. E-mail: tmurama@tsuru.med.nagoya-u.ac.jp
In the present study, we examined the spatiotemporal expression of syndecan-4 during organogenesis of the kidney, whether syndecan-4 is needed for organogenesis of the kidney, and what roles it plays in the mature kidney.

\section{Results}

\section{Expression of Syndecan-4 in the Developing Kidneys of Mouse Embryos}

In situ hybridization for syndecan-4 was performed in the developing kidneys of mouse embryos at 11.5, 13.5, and 15.5 gestational days (gd). At $11.5 \mathrm{gd}$, syndecan-4 expression was detected in the ureteric bud invaginating into the metanephric mesenchyme with slight expression in the metanephric mesenchyme (Fig. 1, A and B). At $13.5 \mathrm{gd}$, syndecan-4 expression was detected in the collecting tubules and metanephric mesenchyme (Fig. 1, C and D). At 15.5 $\mathrm{gd}$, strong expression of syndecan-4 was detected in some renal tubules (Fig. 1, E and F) and also in the glomeruli (Fig. 1F). The sense probe did not give any signals (data not shown).

Immunohistochemical staining confirmed that syndecan-4 was expressed at the protein level in the developing kidney (Fig. 2). Although in situ hybridization detected mRNA expression of syndecan-4 in the metanephric mesenchyme at 11.5 and $13.5 \mathrm{gd}$ (Fig. 1, $B$ and D), immunohistochemical staining did not detect syndecan-4 protein expression in the metanephric mesenchyme except for the renal tubules differentiating from the metanephric mesenchyme (Fig. 2, A and $\mathrm{B})$. It has been reported that syndecan-4 expression is regulated both transcriptionally and post- 


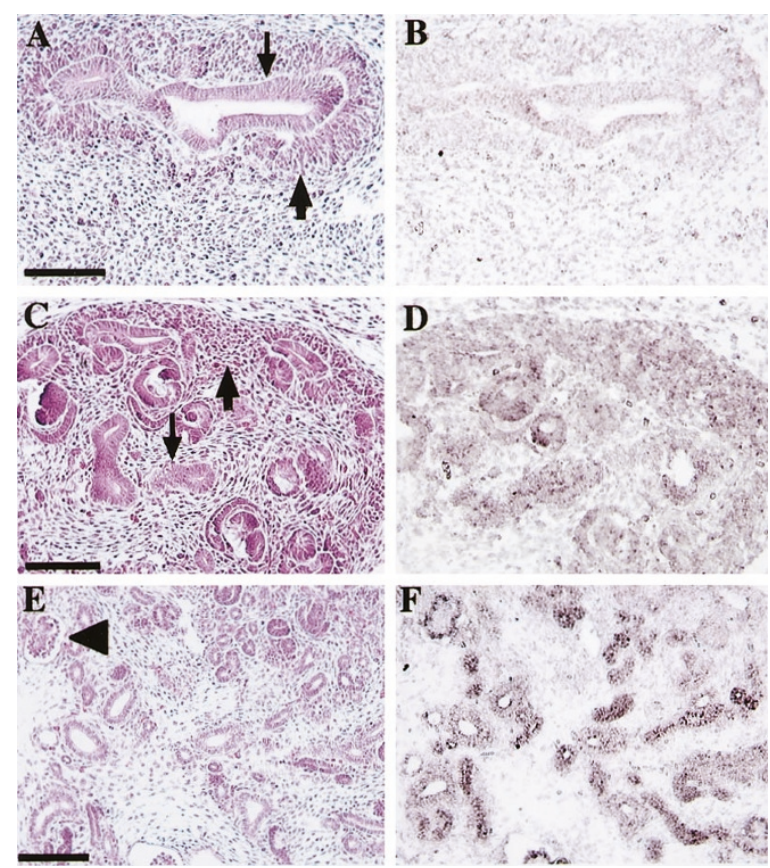

Figure 1.

In situ hybridization of syndecan-4 in the developing kidneys. Hematoxylineosin staining and in situ hybridization of syndecan-4 at 11.5 (A and B), 13.5 $(\mathrm{C}$ and $\mathrm{D})$, and 15.5 gestational days $(\mathrm{gd})(\mathrm{E}$ and $\mathrm{F})$. Thin arrows indicate the ureteric bud invaginating into the metanephric mesenchyme at $11.5 \mathrm{gd}(\mathrm{A})$ and the collecting tubule at $13.5 \mathrm{gd}(\mathrm{C})$. Thick arrows indicate the metanephric mesenchyme ( $A$ and $C)$. The arrowhead indicates the glomerulus $(E)$. Size bars, $100 \mu \mathrm{m}$.

transcriptionally (Zhang et al, 1999). The discrepancy might reflect post-transcriptional regulation in the metanephric mesenchyme that is different from that in the differentiating renal tubules. No signals were seen in the kidneys of syndecan-4-deficient (Synd4[-/-J) embryos by immunohistochemical staining (not shown).

\section{Expression of Syndecan-4 in the Mature Kidney of Adult Mice}

In situ hybridization for syndecan-4 was performed in the mature kidneys of adult mice. Syndecan- 4 expression was detected in the collecting ducts and renal tubules in the papilla and the medulla (Fig. 3A). In the cortex, some renal tubules showed strong syndecan-4 expression (Fig. 3B, arrow). Syndecan-4 expression was also detected in the glomeruli (Fig. 3B, arrowhead). Expression of syndecan-4 was not detected in the kidney of Synd4(-/-) mice by in situ hybridization (Fig. 3C).

Immunohistochemical staining revealed that syndecan-4 was expressed at the protein level in the mature kidney with a profile similar to that observed at the mRNA level (Fig. 4, A to C). Better conservation of tissue structure on immunohistochemical staining enabled us to also detect syndecan-4 expression in some capillaries between renal tubules (Fig. 4D, thick arrow). In the renal tubules, which showed strong syndecan-4 expression in the cortex, Tamm-Horsfall glycoprotein, a marker of the distal renal tubules (Sikri
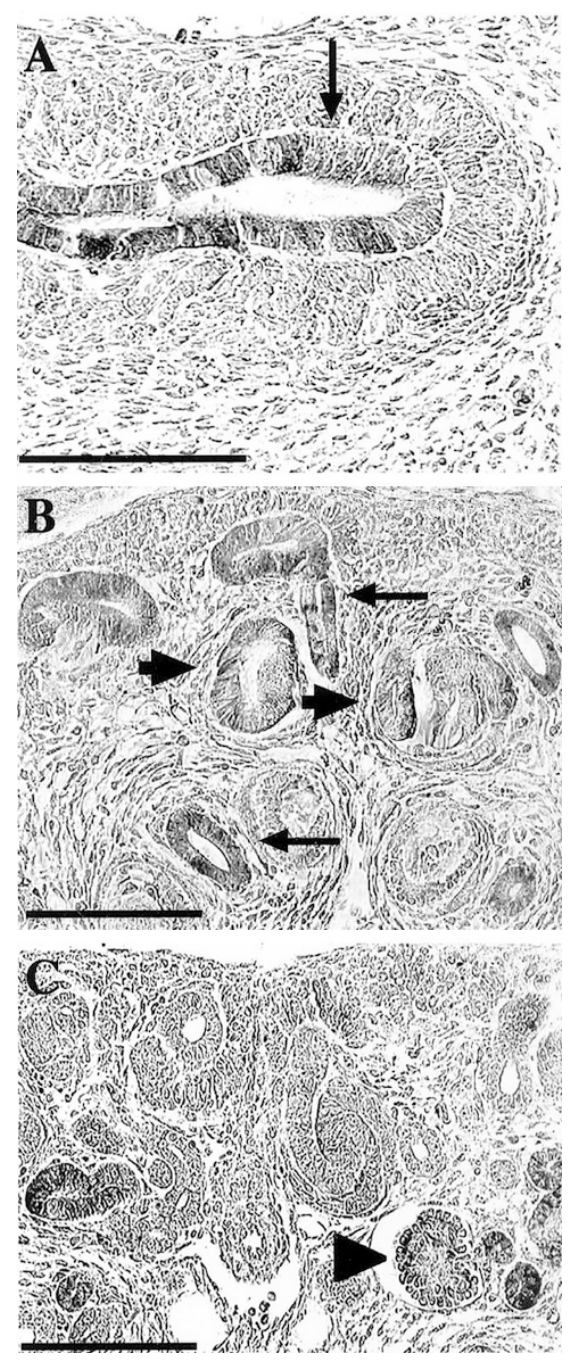

Figure 2.

Immunohistochemical staining of syndecan-4 in the developing kidneys. A, $11.5 \mathrm{gd}$; B, $13.5 \mathrm{gd}$; C, $15.5 \mathrm{gd}$. Thin arrows indicate the ureteric bud invaginating into the metanephric mesenchyme at $11.5 \mathrm{gd}(\mathrm{A})$ and the collecting tubules at $13.5 \mathrm{gd}$ (B). Thick arrows indicate the renal tubules differentiating from the metanephric mesenchyme (B). The arrowhead indicates the glomerulus (C). Size bars, $100 \mu \mathrm{m}$.

et al, 1981), was detected on immunohistochemical staining (Fig. 4, B and E, thin arrows). Expression of syndecan-4 was not detected in the kidney of Synd4(-/-) mice by immunohistochemical staining (Fig. $4 \mathrm{~F})$.

\section{Comparison of Histology and Functions of the Kidney in Synd4(+/+) and Synd4(-/-) Mice}

The histology of the kidneys of embryos and adult mice was not different between Synd4(+/+) and Synd4(-/-) genotypes (not shown). We also investigated the following factors in adult mice of each genotype, but did not find any significant differences between Synd4(+/+) and Synd4(-/-) mice: total volume and specific gravity of 24-hour urine under no stress or dehydration; $\mathrm{pH}$ of urine under no stress or chronic acid loading by $0.24 \mathrm{M} \mathrm{NH}_{4} \mathrm{Cl}$ in drinking water; concentrations of albumin, $\mathrm{Na}^{+}, \mathrm{K}^{+}$, and $\mathrm{Cl}^{-}$in 


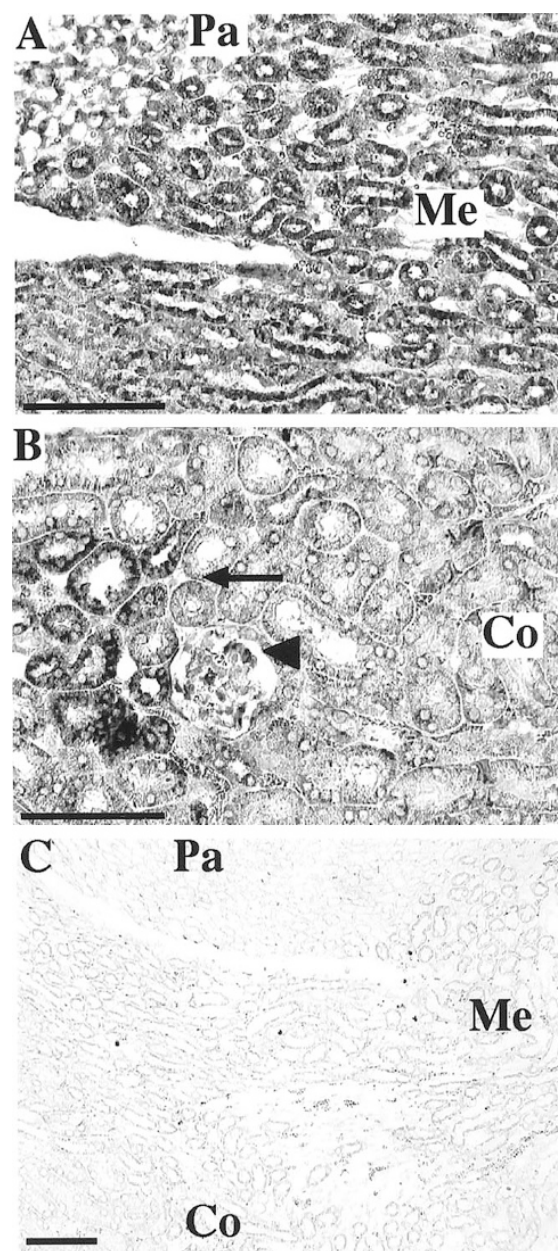

Figure 3.

In situ hybridization of syndecan-4 in the mature kidney. Kidneys of 2-monthold C57BL/6J mice were used, except for $\mathrm{C}$, in which the kidney of a 2-month-old Synd4(-/-) mouse was used. The thin arrow indicates the renal tubules expressing syndecan-4 strongly in the cortex (B). The arrowhead indicates the glomerulus (B). No expression of syndecan-4 was detected in the mature kidney of the Synd4(-/-) mouse (C). Pa, papilla; Me, medulla; Co, cortex. Size bars, $100 \mu \mathrm{m}$.

24-hour urine under no stress (not shown). The level of blood urea nitrogen (BUN) was normal in Synd4(-/-) adult mice.

We then examined possible differences in renal function between Synd4(+/+) and Synd4(-/-) mice after exposure to the following nephrotoxic substances that cause renal damage in different manners: ip injection of cisplatin, which causes damage to the proximal renal tubules (Ward and Fauvie, 1976; Weiner and Jacobs, 1983); bromoethylamine hydrobromide, which causes papillary necrosis via cytotoxicity (Murray et al, 1972); $\kappa$-carrageenan, which causes obstructive nephropathy via its deposition in the collecting ducts (Fowler et al, 1980); and the im injection of glycerol with dehydration, which causes hemoglobinuric acute renal failure (Oken et al, 1966). Administration of cisplatin, bromoethylamine hydrobromide, or glycerol increased BUN to the same level in both Synd4(+/+) and Synd4(-/-) mice (not shown). However, ip injection of $\kappa$-carrageenan at $75 \mathrm{mg} / \mathrm{kg}$ caused death of Synd4(-/-) mice (7 of 24 mice within 7 days), whereas none of the 24 Synd4(+/+) mice examined died (Fig. 5). BUN was increased more markedly in surviving Synd4(-/-) mice than in Synd4(+/+) mice on Days 1 and 4 after injection (Fig. 6) $(p<0.05)$.

To investigate the cause of death, $\kappa$-carrageenan at $75 \mathrm{mg} / \mathrm{kg}$ was injected to 16 additional Synd4(-/-) mice, and four mice, which appeared sick, were examined on Days 2 and 4 after injection. In these animals, BUN exceeded $150 \mathrm{mg} / \mathrm{dl}(164.62 \pm 5.36$ $\mathrm{mg} / \mathrm{dl}$, mean $\pm \mathrm{SE})$. Histologic analysis demonstrated that renal tubules were dilated and the inner medulla was severely degenerated (Fig. 7, B and D). These changes were much less marked in Synd4(+/+) mice on Days $2(n=8)$ and $4(n=16)$ after injection (Fig. 7, $A$ and $C)$. No severe damage was observed in the brain, heart, lungs, or liver of Synd4(+/+) or Synd4(-/-) mice on Day 2 or 4 (not shown). Alcian blue staining at $\mathrm{pH} 1.0$ demonstrated more extensive deposition of alcianophilic material, which was considered to be largely $\kappa$-carrageenan (Fowler et al, 1980; Gangolli et al, 1973), in the inner medulla of Synd4(-/-) (Fig. 7F) than in Synd4(+/+) mice (Fig. 7E). The identity of material deposited in the inner medulla was confirmed to be $\kappa$-carrageenan by immunohistochemical staining with antiserum to carrageenans (Fig. 8A).

\section{Discussion}

The kidney contains two epithelia with distinct origins: urinary collecting ducts formed by growth and arborization of the ureteric bud, and excretory nephrons differentiating via a mesenchyme-epithelium transition induced by the invaginating ureteric bud (Davies et al, 1995; Grobstein, 1953; Lechner and Dressler, 1997). Proteoglycans are required for maintenance of Wnt-11 expression in the ureter tip (Kispert et al, 1996), especially sulfated proteoglycans for collecting duct growth and branching (Davies et al, 1995). The presence of heparan sulfate is essential for organogenesis of the kidney, because disruption of heparan sulfate 2-sulfotransferase abolishes the process (Bullock et al, 1998).

The present study demonstrated syndecan-4 expression in the developing kidney as early as $11.5 \mathrm{gd}$ and at late stages of gestation. Syndecan-4 could be one of the HSPG involved in organogenesis of the kidney. However, Synd4(-/-) mice did not show any abnormalities in kidney histology. Syndecan-1 expression appears in the mesenchyme around the invaginating ureteric bud, and its expression increases as the mesenchyme differentiates into renal tubules and then decreases as development of the kidney proceeds (Vainio et al 1989). Syndecan-2 expression is detected in the mesenchyme surrounding renal tubules in the kidney at 13 gd (David et al, 1993). In addition to syndecans, the developing kidney expresses another cell surface HSPG family, the glypican family: glypican-1 (Litwack et al, 1998), -3 (Pilia et al, 1996), -4 (Watanabe et al, 1995), and -5 (Saunders et al, 1997; Veugelers et al, 1997). These HSPG could function sufficiently for organogenesis of the kidney even in Synd4(-/-) embryos. 

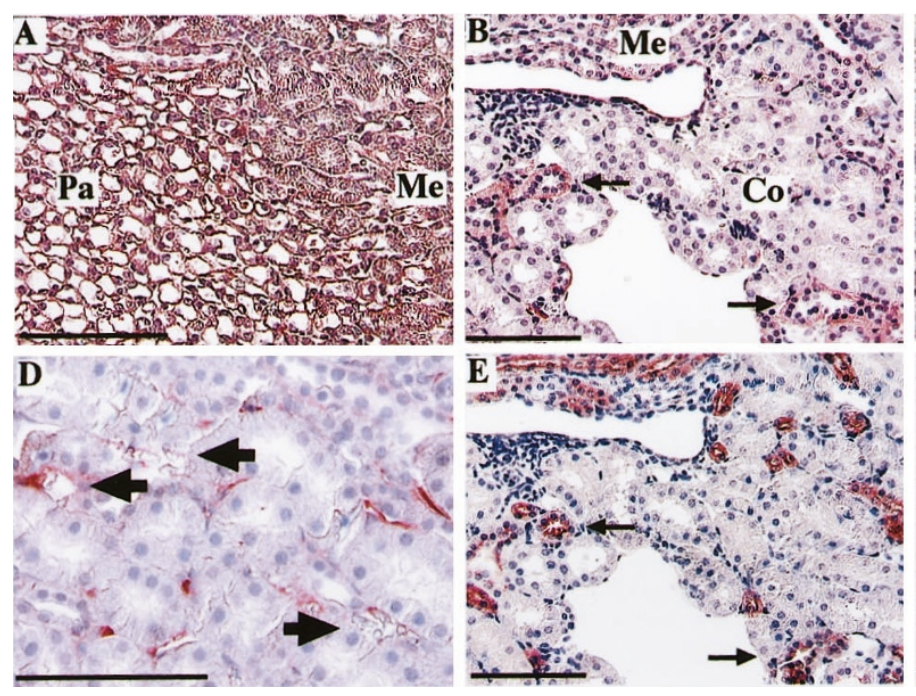

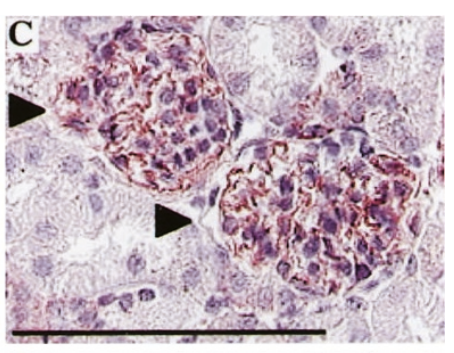

F Pa

Me

Figure 4.

Immunohistochemical staining of syndecan-4 (A to D, and F) and Tamm-Horsfall glycoprotein ( $E$, the section adjacent to B) in the mature kidney, counterstained with hematoxylin (except F). Kidneys from 2-month-old C57BL/6J mice were used, except for F, in which the kidney from a 2-month-old Synd4(-/-) mouse was used. Thin arrows indicate the renal tubules expressing syndecan-4 strongly in the cortex (B), which also express Tamm-Horsfall glycoprotein (E). Arrowheads indicate the glomeruli (C). Thick arrows indicate the capillaries expressing syndecan-4 (D). Pa, papilla; Me, medulla; Co, cortex. Size bars, $100 \mu \mathrm{m}$.

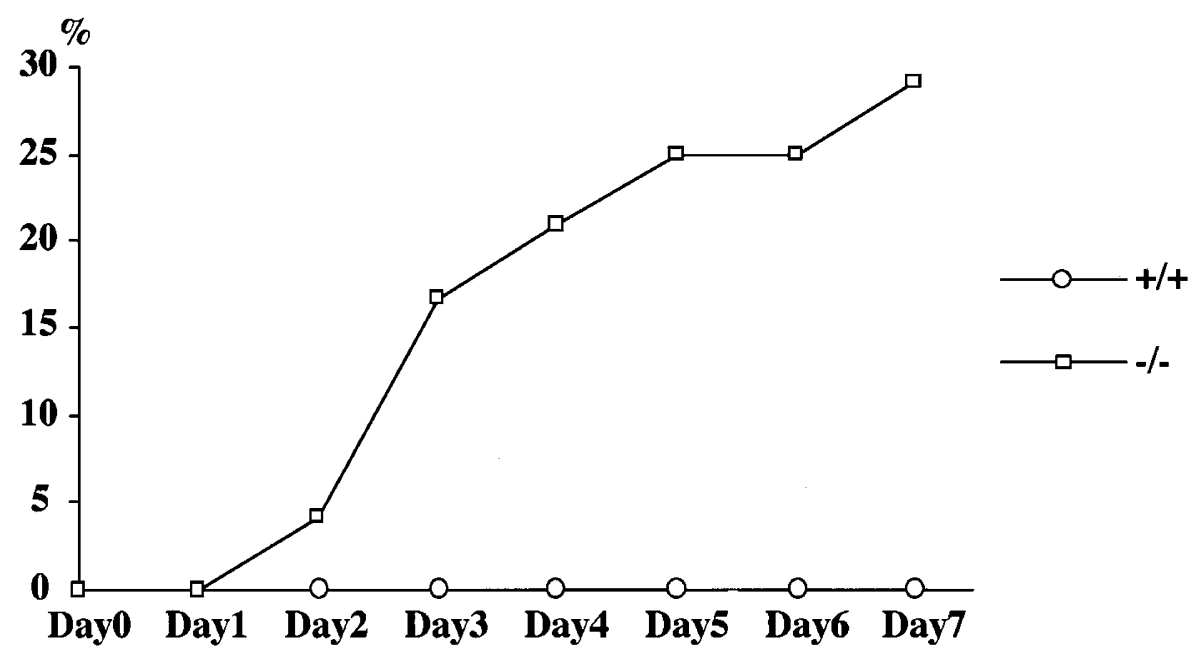

Figure 5.

Mortality after ip injection of $\kappa$-carrageenan at $75 \mathrm{mg} / \mathrm{kg}$. Twenty-four 2-month-old male mice of each genotype were used. Weight was matched between the groups $(23.0 \pm 0.5 \mathrm{~g}$, mean $\pm \mathrm{SE})$. Within 7 days after injection, seven Synd4(-/-) mice died. +/+, Synd4(+/+) mice; -/, Synd4(-/-) mice.

In adult mice, syndecan-4 expression was detected in the collecting ducts and renal tubules in the papilla and the medulla. In the cortex, some renal tubules showed strong syndecan-4 expression and they also expressed Tamm-Horsfall glycoprotein, which is known to be expressed in the distal tubules (Sikri et al, 1981), indicating that syndecan-4 is strongly expressed in some distal tubules in the cortex. Syndecan-4 expression was also detected in the glomeruli and some capillaries between renal tubules. Nevertheless, most of the renal functions of Synd4(-/-) mice were normal. Similarly to the developing kidney, the mature kidney expresses various HSPG in addition to syndecan-4: perlecan and agrin in the glomeruli (Groffen et al, 1999); CD44 in the glomeruli, cortical tubules, and interstitial cells (Jun et al, 1997); L- selectin-reactive HSPG in the distal tubules (Watanabe et al, 1999); and glypican-1 in the glomeruli (Pyke et al, 1997). Thus, these HSPG could function to maintain renal functions even in Synd4(-/-) mice.

The ip injection of $\kappa$-carrageenan at $75 \mathrm{mg} / \mathrm{kg}$ caused death of Synd4(-/-) mice with a mortality rate of $29.2 \%$, whereas none of the Synd $4(+/+)$ controls died within 7 days. Compared with Synd4(+/+) controls, BUN was increased more markedly in Synd4(-/-) mice. In the kidneys of Synd4(-/-) mice injected with $\kappa$-carrageenan, the dilation of renal tubules and degeneration of the inner medulla were extensive and severe. Moreover, Alcian blue staining at $\mathrm{pH} 1.0$ and immunohistochemical staining with antiserum to carrageenans detected extensive deposition of $\kappa$-carrageenan in the inner medulla. Carrageenans 


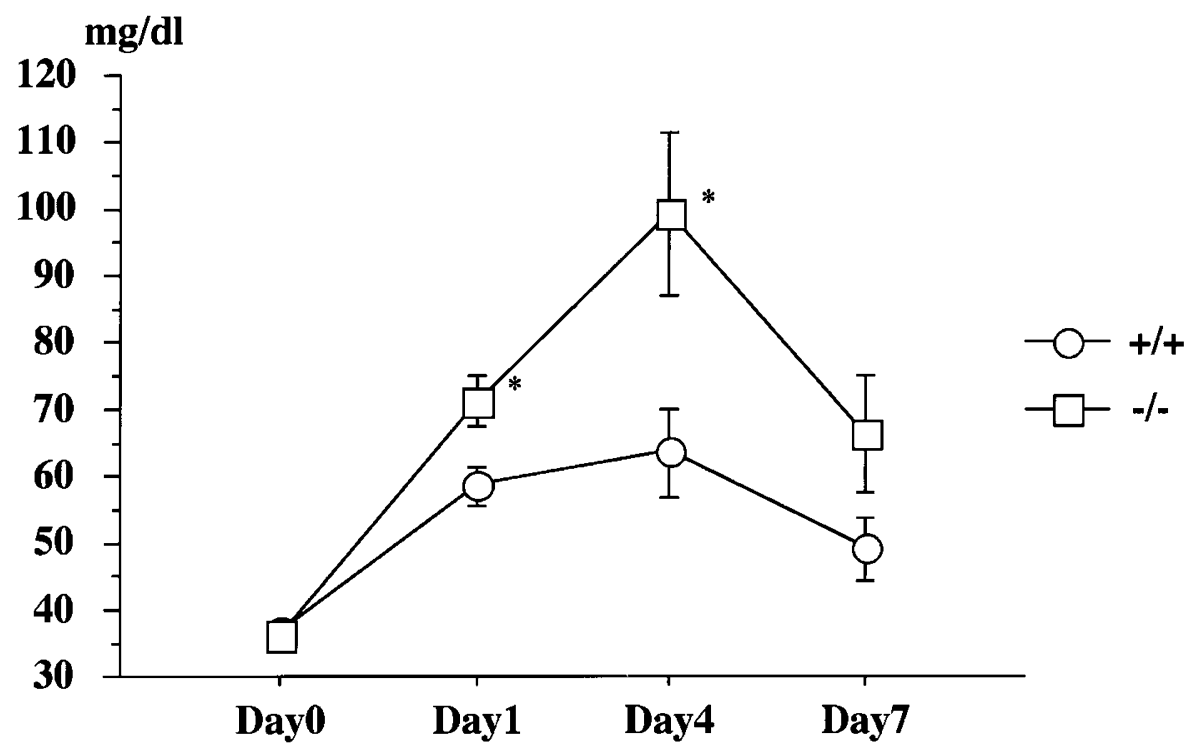

Figure 6.

Blood urea nitrogen after ip injection of $\kappa$-carrageenan at $75 \mathrm{mg} / \mathrm{kg}$. The same mice as in Figure 5 were evaluated. Surviving Synd4(-/-) mice at each time point were evaluated. Values are shown as means \pm SE. Statistical significance was calculated by Student's $t$ test $($ Day 1$)$ or Welch's $t$ test $($ Day 4$)$. * $P<0.05 ;+/+, S y n d 4(+/+)$ mice; -/, Synd4(-/-) mice.

cause obstructive nephropathy via their deposition in the collecting ducts (Fowler et al, 1980). These observations suggested that $\kappa$-carrageenan was deposited extensively in the collecting ducts and the deposited $\kappa$-carrageenan caused degeneration of the inner medulla in the kidneys of Synd4(-/-) mice, leading to obstructive nephropathy. No severe damage was observed in the brain, heart, lungs, or liver of Synd4(-/-) mice on Day 2 or 4 . Thus it is likely that death of $\kappa$-carrageenan-treated Synd4(-/-) mice was due to obstructive nephropathy caused by severe deposition of $\kappa$-carrageenan in the collecting ducts. Syndecan- 4 expressed in the collecting ducts may prevent the deposition of $\kappa$-carrageenan, although the precise mechanism remains to be elucidated.

\section{Materials and Methods}

\section{Materials}

$\kappa$-Carrageenan was purchased from Sigma-Aldrich (St. Louis, Missouri) and diluted with sterile distilled water to $2.5 \mathrm{mg} / \mathrm{ml}$ for ip injection. Cisplatin (BristolMyers Squibb, New York, New York), bromoethylamine hydrobromide (Wako, Osaka, Japan), and glycerol (Nacalai Tesque, Kyoto, Japan) were also used to induce renal damage (Murray et al, 1972; Oken et al, 1966; Ward and Fauvie, 1976; Weiner and Jacobs, 1983).

\section{Organs}

For in situ hybridization and immunohistochemical staining, embryos were obtained from pregnant C57BL/6J mice (Clea, Tokyo, Japan) on 11.5, 13.5, and $15.5 \mathrm{gd}$. Kidneys of adult mice were also obtained from $\mathrm{C} 57 \mathrm{BL} / 6 \mathrm{~J}$ mice at 8 weeks old.
The samples were fixed in $4 \%$ paraformaldehyde/ Dulbecco's phosphate-buffered saline without calcium and magnesium (PBS $[-]$ ) at $4^{\circ} \mathrm{C}$ overnight for in situ hybridization and immunohistochemical staining, or in Carnoy's solution (methanol : chloroform : acetic acid $=6: 3: 1$ ) for periodic acid Schiff staining, Alcian blue staining, and immunohistochemical staining. Samples were dehydrated and embedded in paraffin wax. Sections (6- $\mu \mathrm{m}$ thick) were mounted on 3-aminopropyltriethoxysilane-coated slide glasses (Matsunami Glass, Osaka, Japan).

\section{Generation of Targeted Mice}

Synd4(+/-) mice were produced by mating female C57BL/6J mice with the male chimeric mouse carrying Synd4(+/-) embryonic stem (ES)-derived cells, which were generated by homologous recombination as previously described (Ishiguro et al, 2000b). After the Synd4(+/-) mice were backcrossed six times to C57BL/6J mice, the Synd4(+/-) mice were mated with each other to produce Synd4(+/+) and Synd4(-/-) mice. The frequency of the genotypes of mice matched the Mendelian ratios.

\section{In Situ Hybridization}

The antisense and sense RNA probes of syndecan-4 were prepared as previously described (Ishiguro et al, 1999). In situ hybridization was performed as previously described (Fan et al, 1998).

\section{Immunohistochemical Staining}

The rabbit antimouse syndecan- 4 ectodomain antibody was prepared as previously described (Ishiguro et al, 1999). The antibody was used at 1:50 dilution. 

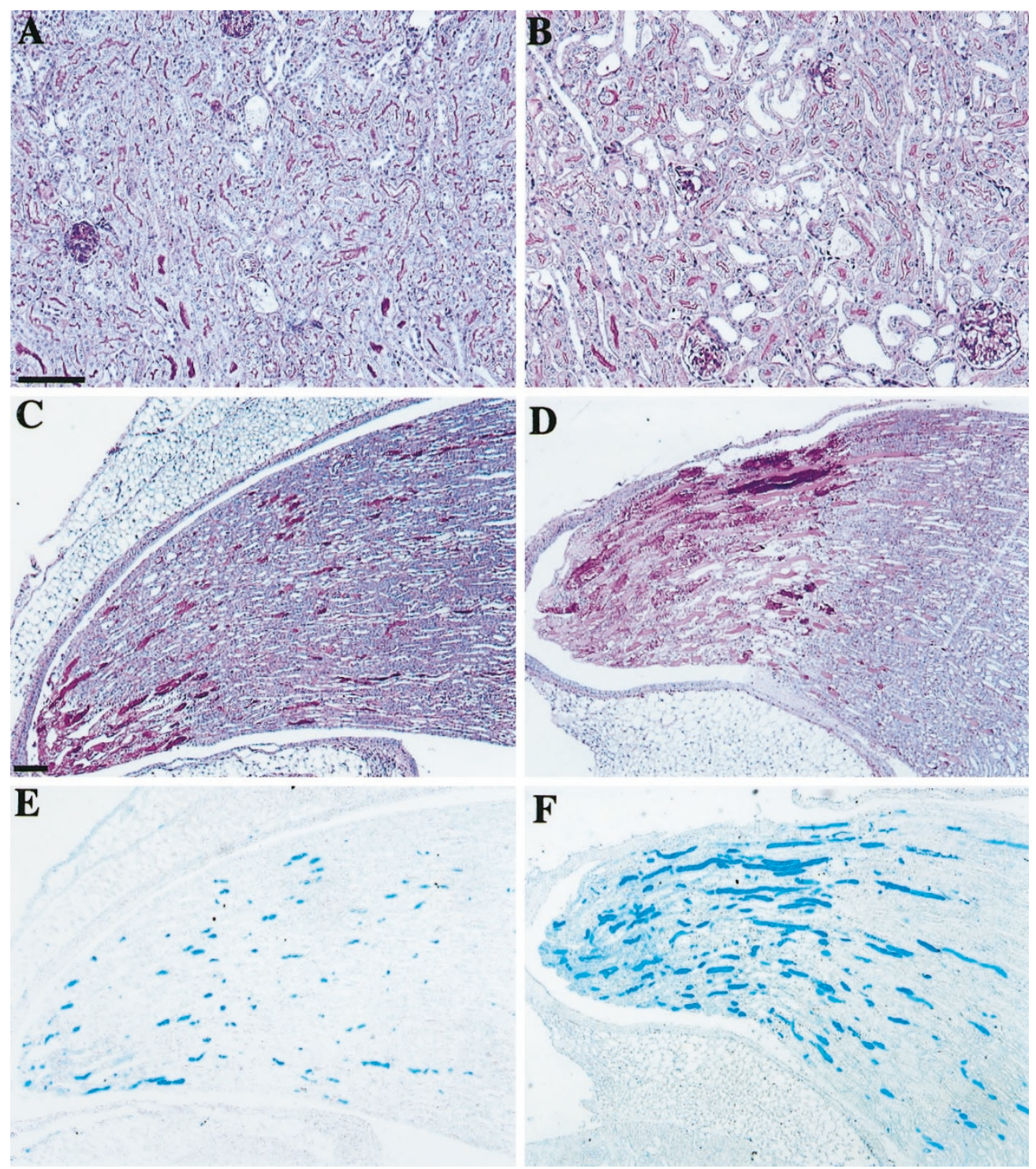

\section{Figure 7.}

Periodic acid Schiff (PAS) staining and Alcian blue staining at pH 1.0. Kidneys were used at Day 4 (Synd4[+/+ ] mouse; A, C, and E) or Day 2 (Synd4[-/-] mouse; $\mathrm{B}, \mathrm{D}$, and F) after ip injection of $\kappa$-carrageenan at $75 \mathrm{mg} / \mathrm{kg}$. PAS staining of the renal cortex and inner medulla of Synd4(+/+) (A and C) and Synd $4(-/-)$ mice (B and D). Alcian blue staining at $\mathrm{pH} 1.0$ of the inner medulla of Synd4(+/+) (E) and Synd4(-/-) mice (F). Size bars, $100 \mu \mathrm{m}$.

Contaminants, if any, were absorbed with dry powder derived from placentas and embryos obtained by mating Synd4(-/-) mice. After incubation with the first antibody at room temperature for 1 hour or at $4^{\circ} \mathrm{C}$ overnight, sections were incubated with antirabbit IgG antibody conjugated with biotin, followed by avidinbiotinylated peroxidase complex. Staining was visualized with aminoethylcarbazole (Dako, Carpinteria, California) or diaminobenzidine tetrahydrochloride- $\mathrm{Ni}^{3+}$, $\mathrm{Co}^{2+}$ (Amersham Pharmacia Biotech, Tokyo, Japan).

The sheep anti-Tamm-Horsfall glycoprotein antibody was purchased from Cell \& Molecular Technologies (Phillipsburg, New Jersey) and used at 1:20 dilution. The sheep antiserum to carrageenans was purchased from Guildhay Limited (Guildford, United Kingdom) and used at 1:100 dilution. After incubation with the first antibody or antiserum at room temperature for 1 hour or at $4^{\circ} \mathrm{C}$ overnight, respectively, sections were incubated with antigoat IgG antibody conjugated with horseradish peroxidase. Staining was visualized with aminoethylcarbazole or diaminobenzidine tetrahydrochloride- $\mathrm{Ni}^{3+}, \mathrm{Co}^{2+}$.

\section{BUN Assay}

With the mice under mild anesthesia with diethyl ether, $100 \mu \mathrm{l}$ of blood was taken from the orbital vein. After incubation for 30 minutes at room temperature, serum was separated by centrifugation at $5,000 \times g$ for 10 minutes. BUN was determined with Urea N B (Wako) according to the manufacturer's instructions.

\section{Statistical Analysis}

Stat View 4.5 (Abacus Concepts, Berkeley, California) was used for statistical analyses. 


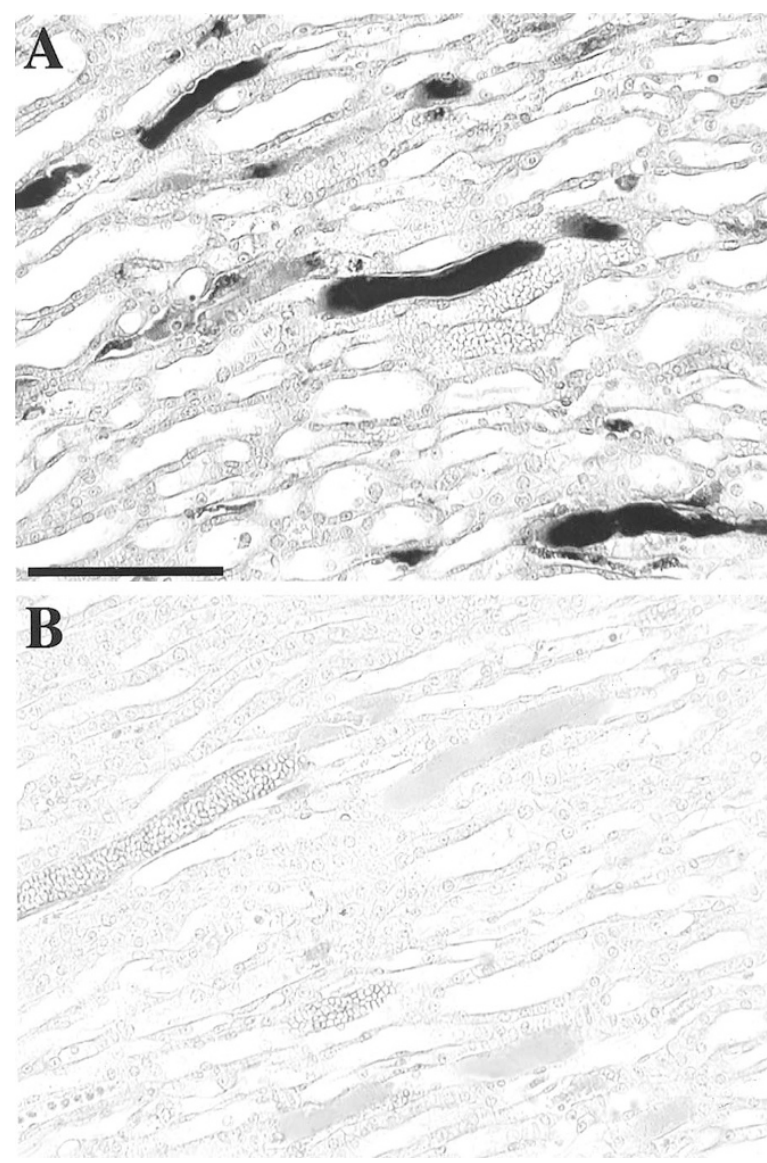

Figure 8.

Immunohistochemical staining of carrageenans in the inner medulla of the kidney of the Synd $4(-/-)$ mouse on Day 2 after ip injection of $\kappa$-carrageenan at $75 \mathrm{mg} / \mathrm{kg}$. Antiserum to carrageenans (A) or normal goat serum (B) was used.

\section{Acknowledgements}

We thank Ms. Yamafuji for technical support.

\section{References}

Bullock SL, Fletcher JM, Beddington RS, and Wilson VA (1998). Renal agenesis in mice homozygous for a gene trap mutation in the gene encoding heparan sulfate 2-sulfotransferase. Genes Dev 12:1894-1906.

David G, Bai XM, Van der Schueren B, Marynen P, Cassiman JJ, and Van den Berghe H (1993). Spatial and temporal changes in the expression of fibroglycan (syndecan-2) during mouse embryonic development. Development 119:841-854.

Davies J, Lyon M, Gallagher J, and Garrod D (1995). Sulphated proteoglycan is required for collecting duct growth and branching but not nephron formation during kidney development. Development 121:1507-1517.

Fan Q-W, Yuasa S, Kuno N, Senda T, Kobayashi M, Muramatsu T, and Kadomatsu K (1998). Expression of basigin, a member of the immunoglobulin superfamily, in the mouse central nervous system. Neurosci Res 30:53-63.

Fowler EF, Simpson JG, and Thomson AW (1980). Histological and ultrastructural changes following carrageenan injection in the mouse. J Pathol 132:63-79.
Gangolli SD, Wright MG, and Grasso P (1973). Identification of carrageenan in mammalian tissues: An analytical and histochemical study. Histochem J 5:37-48.

Grobstein C (1953). Inductive epithelio-mesenchymal interaction in cultured organ rudiments of the mouse. Science 118:52-55.

Groffen AJ, Veerkamp JH, Monnens LA, and van den Heuvel LP (1999) Recent insights into the structure and functions of heparan sulfate proteoglycans in the human glomerular basement membrane. Nephrol Dial Transplant 14:21192129.

Horowitz A and Simons M (1998). Regulation of syndecan-4 phosphorylation in vivo. J Biol Chem 273:10914-10918.

Ishiguro K, Kojima T, Taguchi O, Saito H, Muramatsu T, and Kadomatsu K (1999). Syndecan-4 expression is associated with follicular atresia in mouse ovary. Histochem Cell Biol 112:25-33.

Ishiguro K, Kadomatsu K, Kojima T, Muramatsu H, Nakamura E, Ito M, Nagasaka T, Kobayashi H, Kusugami K, Saito H, and Muramatsu T (2000a). Syndecan-4 deficiency impairs the fetal vessels in the placental labyrinth. Dev Dyn 219:539-544.

Ishiguro K, Kadomatsu K, Kojima T, Muramatsu H, Tsuzuki S, Nakamura E, Kusugami K, Saito $\mathrm{H}$, and Muramatsu T (2000b). Syndecan-4 deficiency impairs focal adhesion formation only under restricted conditions. J Biol Chem 275: $5249-5252$.

Jun Z, Hill PA, Lan HY, Foti R, Mu W, Atkins RC, and Nikolic-Paterson DJ (1997). CD44 and hyaluronan expression in the development of experimental crescentic glomerulonephritis. Clin Exp Immunol 108:69-77.

Kim CW, Goldberger OA, Gallo RL, and Bernfield M (1994). Members of the syndecan family of heparan sulfate proteoglycans are expressed in distinct cell-, tissue-, and development-specific patterns. Mol Biol Cell 5:797-805.

Kispert A, Vainio S, Shen L, Rowitch DH, and McMahon AP (1996). Proteoglycans are required for maintenance of Wnt-11 expression in the ureter tips. Development 122:36273637.

Kojima T, Leone CW, Marchildon GA, Marcum JA, and Rosenberg RD (1992a). Isolation and characterization of heparan sulfate proteoglycans produced by cloned rat microvascular endothelial cells. J Biol Chem 267:4859-4869.

Kojima T, Shworak NW, and Rosenberg RD (1992b). Molecular cloning and expression of two distinct cDNA-encoding heparan sulfate proteoglycan core proteins from a rat endothelial cell line. J Biol Chem 267:4870-4877.

Kojima T, Katsumi A, Yamazaki T, Muramatsu T, Nagasaka T, Ohsumi K, and Saito H (1996). Human ryudocan from endothelium-like cells binds basic fibroblast growth factor, midkine, and tissue factor pathway inhibitor. $\mathrm{J}$ Biol Chem 271:5914-5920.

Lechner MS and Dressler GR (1997). The molecular basis of embryonic kidney development. Mech Dev 62:105-120.

Litwack ED, Ivins JK, Kumbasar A, Paine-Saunders S, Stipp CS, and Lander AD (1998). Expression of the heparan sulfate proteoglycan glypican-1 in the developing rodent. Dev Dyn 211:72-87.

Murray G, Wyllie RG, Hill GS, Ramsden PW, and Heptinstall RH (1972). Experimental papillary necrosis of the kidney. I. Morphologic and functional data. Am J Pathol 67:285-302. 
Oken DE, Arce ML, and Wilson DR (1966). Glycerol-induced hemoglobinuric acute renal failure in the rat. I. Micropuncture study of the development of oliguria. J Clin Invest 45:724735.

Pilia G, Hughes-Benzie RM, MacKenzie A, Baybayan P, Chen EY, Huber R, Neri G, Cao A, Forabosco A, and Schlessinger D (1996). Mutations in GPC3, a glypican gene, cause the Simpson-Golabi-Behmel overgrowth syndrome. Nat Genet 12:241-247.

Pyke C, Kristensen P, Ostergaard PB, Oturai PS, and Romer $\mathrm{J}$ (1997). Proteoglycan expression in the normal rat kidney. Nephron 77:461-470.

Saunders S, Paine-Saunders S, and Lander AD (1997). Expression of the cell surface proteoglycan glypican-5 is developmentally regulated in kidney, limb, and brain. Dev Biol 190:78-93.

Sikri KL, Foster CL, MacHugh N, and Marshall RD (1981). Localization of Tamm-Horsfall glycoprotein in the human kidney using immuno-fluorescence and immuno-electron microscopical techniques. J Anat 132:597-605.

Vainio S, Lehtonen E, Jalkanen M, Bernfield M, and Saxen L (1989). Epithelial-mesenchymal interactions regulate the stage-specific expression of a cell surface proteoglycan, syndecan, in the developing kidney. Dev Biol 134:382-391.
Veugelers M, Vermeesch J, Reekmans G, Steinfeld R, Marynen P, and David G (1997). Characterization of glypican-5 and chromosomal localization of human GPC5, a new member of the glypican gene family. Genomics 40:24-30.

Ward JM and Fauvie KA (1976). The nephrotoxic effects of cis-diammine-dichloroplatinum (II) (NSC- 119875) in male F344 rats. Toxicol Appl Pharmacol 38:535-547.

Watanabe K, Yamada H, and Yamaguchi $Y$ (1995). K-glypican: a novel GPI-anchored heparan sulfate proteoglycan that is highly expressed in developing brain and kidney. J Cell Biol 130:1207-1218.

Watanabe N, Kawashima H, Li YF, and Miyasaka M (1999). Identification and characterization of ligands for L-selectin in the kidney. III. Characterization of L-selectin reactive heparan sulfate proteoglycans. J Biochem 125:826-831.

Weiner MW and Jacobs C (1983). Mechanism of cisplatin nephrotoxicity. Fed Proc 42:2974-2978.

Woods A and Couchman JR (1994). Syndecan 4 heparan sulfate proteoglycan is a selectively enriched and widespread focal adhesion component. Mol Biol Cell 5:183-192.

Zhang Y, Pasparakis M, Kollias G, and Simons M (1999). Myocyte-dependent regulation of endothelial cell syndecan-4 expression. J Biol Chem 274:14786-14790. 